\title{
ABSTRACTS Meeting of the European Society for Pediatric Research
}

\author{
Stockholın, Sweden, August 25-29, 1970
}

1. Evidence for two different biochemical defects causing Sanfilippo syndrome. U. N. Wirsmann and F. F. Nrufeld, Univ. of Bem, Switzerland and NJH, Bethesda, Md., USA.

The Sanfilippo syndrome is characterized by storage of heparitinsulfate (HS) and chondroitinsulfate (CH-B) in liver and spleen, excretion of large amounts of HS in urine, moderate skeletal involvement, and severe mental retardation. Cultivated skin fibroblasts from paticnts accumulate abnormal amounts of CH-B intracellularly. A defect in lysosomal degradation of mucopolysaccharides (MPS) is shown by intracellular incorporation of $S^{35} \mathrm{O} 4$ into MPS and by the rate of disappearance of the label from prelabeled cells. The foulthy degradation can be normalized either by mixing the cells from the patient with normal fibroblasts or by addition of preincubated media-faction (precipitated at $80 \% \mathrm{NH}_{4} \mathrm{SO}_{4}$ ) collected from normal cell lines or cells from other types of mucopolysaccharidosis. It is concluded that individual cell lines can substitute each other with specilic factors they lack originally. In case of Sanfilippo cells the missing factor is not dialyzable and is heat-labile. Crosscorrection was not obtained by mixing cell lines from some patiens: other cell lines, however, did mutually correct each other. Thus, two different types of the clinically identical Sanfilippo syndrome could be established. Cell lines of the same type do not substitute each other for the factor, but their MPS metabolism is corrected by any other cell line, including the other Santilippo type. Affected members of the same family show the same type, indicating the presence of true genetic variants. Equal distribution of the two types was found in a larger group of Sanfilippo pattients. There is evidence that at least two different biochemical defects in MPS metabolism can cause the clinical picture of the Sanfilippo syndiome.

2. Fuzyme replatement in Fabry's discase. W. KkIvir, R. J.

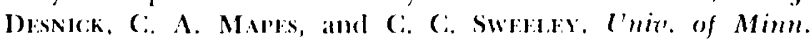
Med. Sch. Mimnenpolis, Minn. and Mich. State Unir., East I.ansing, Mich., USA.

Fabry's disease was originally conceived diagnostically as a dermatological disorder (angiokeratoma). The systemic manifestations due to blood vessel involvement of renal, cardiac, and neural tisstes widened the spectrum of clinical disease. The earlicst manifestations ocem in childhoed and are at confusing diagnostic problem. The scope of the disease lats been enlanged and manifested by the female heterosgene and be he several "forme fruste" gentetic vatiatus in males without shin lesions. Recent studies have provided explicit konewledge atomet the metabolic abnormality. Increased levels of galactoss-galactestlglyeosyl ceranide (CII-3) in blood, urine sediment, and most tissues have been consistently noted (J. Lipid Res., 10: 188, 1969 and 11: 31, 1970). These are correlated with the absence of a specific galactosyl hydrolase in hemizygotes. Heterozygous females have intermediate levels of the lipid and partial deficiency of the enzyme. Recently, the same galactosyl hydrolase which is absent in patients with Fabry's disease has been found in normal blood plasma. This suggested the possibility of direct enzyme therapy by plasma transfer. Six hours after the plasma infusion an "enhanced" or "induced" level of enzyme was noted. This level was 20 -fold greater in the recipient than could be accounted for by the amount from the donor. Therapy with plasma in. fusion is under active investigation at present.

3. Camosinase deficiency related to development of carnosinase activity. J. M. F. Trijber.s, P. J. van Hefswijk, P. J. J. van Munstf.r, and E. D. A. M. Schrfti.f. Univ. of Nijmegen, Nijmegen, The Netherlands.

$A$ patient suffering from a progessive neurological disorder with severe mental retardation excreted increased amounts of camosine ( $\beta$-alanyl-histidine) in urine. A strongly decreased activity of camosinase was found in the scrum of this patient, who is the first child of healthy consanguineous parents. Two patients with identical abnormalities have been described by Perry et al. [1]. In order to detect other patients with such a, presumably genetically determined, deficiency of serum carnosinase activity, a new method has been developed for the determination of the enzymic activity using 1 -carnosine-( $\beta$-alanyl$\mathrm{I}^{11} \mathrm{C}$ ) as a substrate. The serum carnosinase activity was calculated from the ratio disintegrations per minute $\beta$-alanine: total disimegrations per minute. The carmosinase activity had been determined in the serum of newbons, older children, and adults. 1)uring the first 10 years of life a striking correlation was established between the measured serum carnosinase activity and the age of the human subject. Newborns possess only very low activities (maximally $0.1 \mathrm{unit} / \mathrm{liter}$ during the first 50 days of life whereats children above the age of 10 years have activities between 20 and 70 units/liter, a range found for the enzymic activities in serum of 40 adults, varying in age between 20 and 11 years. This relationship between age of the subjects and the measured enzymic activities has to be considered in view of detection of more patients with the described dipeptiduria, which probably can be classified as a mo-threshold type.

I. Prekt, I'. I., Ilanste, S., l'ischllek, B., Bunting, R., and BH RKY, K.: New F.ngl. J. M(“1., 277: 1219 (1967).

1. Iyperpropionic acielemia in ketotic hyperglycinemia. I. M.

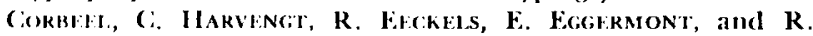
VAN DRIFscine. Unitu. of Leuten, Belgium.

The patient, a 4-week-old female infant with vomiting, anemia, 